\section{Menstrual myths, morals and milestones: a paediatric miasma}

\author{
Margaret Zacharin
}

For many members of the community, menstruation remains one of the few remaining human mysteries and is the subject of myth and misinformation. As fertility and childbirth continue to be intrinsic to human survival, understanding the menstrual cycle is of pivotal importance.

Many subjects in clinical medicine have been the victim of beliefs profoundly held and with little basis other than an expert opinion. In recent years, expansion of technology, better understanding of physiology and the genetic basis of many disorders have provided hitherto impossible insights into mechanisms of disease. These changes have allowed new interventions with reduced morbidity and better health outcomes. Progress through puberty with

Murdoch Children's Research institute, Royal Children's Hospital, Melbourne, Victoria, Australia

Correspondence to Professor Margaret Zacharin, Endocrinology, Royal Children's Hospital, Melbourne, Victoria, Australia; Margaret.Zacharin@rch.org.au established menstruation is considered to reflect a reasonable standard of general health in girls. The paper by Pena and colleagues ${ }^{1}$ describes patterns of ovulation and thus expectation of fertility in adolescent girls with irregular menstruation, demonstrating that most cycles are ovulatory, contrary to accepted beliefs.

In some countries, the discipline of paediatrics still ends at age 12 , in others it is $15-16$ years and for a majority transition takes place either at age 18 or at the end of secondary schooling. Despite variations in the age of transition for many medical conditions, in institutions that care for increasingly complex conditions of childhood, concerns have even been raised that some childhood-onset conditions may need longer-term care of paediatricians in order to preserve continuity and trust. ${ }^{2}$ Thus the role of the paediatrician has continued to expand, and knowledge of the menstrual cycle and fertility has become a necessary part of practice.
Not only does the modern paediatrician need to understand normal physiological processes for every adolescent girl, but changes in population growth patterns and complex health disorders have increased the need for better understanding of variations inherent in many conditions.

In paediatrics, it is well recognised that epigenetic changes influence specific future metabolic risks in small for gestational age infants, many of whom will undergo early puberty, a postulated accelerated maturational and fertility trajectory. A shift has occurred in the past century ${ }^{3}$ from transgenerational transmission of epigenetic changes that favour earlier puberty in circumstances of economic restriction and low body weight, through better prevailing conditions, with later onset of puberty and fecundity, to what has, ongoing from the latter part of the 20th century, become an accelerating epidemic of childhood and adult obesity, reflected in early rapid linear growth and pubertal onset but with concomitant risks for metabolic syndrome, polycystic ovary syndrome (PCOS) in women and impaired future fertility.

Paediatric practice has changed over the last 30 years, with increased incidence of some conditions such as inflammatory bowel disease, increased survival after childhood cancer, for those with 
disabilities, with organ transplantation and with neuromuscular disorders. Many of these young people will have absent, delayed or disordered puberty and will need competent advice and treatment. Others will have unpredictable recovery from pubertal failure with normalisation of ovulation for girls and thus may suddenly become at potential risk for unexpected or unwanted pregnancy.

Despite this knowledge, many paediatricians remain largely unaware of some of the physiological aspects of puberty. The enormous influence of puberty on growth, bone mass accrual and psychosocial development is well recognised, but normal events of menstruation, menstrual irregularity and associated problems frequently remain in the sphere of gynaecologists. Plotting of growth trajectories and pubertal Tanner staging is not always regularly performed or noted in many disciplines. Knowledge regarding adolescent sexual practices and contraception constitutes a minimal part of undergraduate and postgraduate teaching programmes in many institutions. How then is knowledge of normal physiology to progress? Who then will seek information as to when ovulation will commence and potential for fertility will occur and, by extension, who will be at risk and who will need consideration for contraception and when? Transition of discussion focus from parent to adolescent, with new topics of sex and contraceptive needs and options, remains foreign to many paediatricians. Rather than breach long-established trust by wading into uncharted waters, the topic may be avoided by both parties, with potential for catastrophic physical, social and emotional outcomes. There is an urgent need for better education in this field, so that paediatricians feel comfortable and competent to discuss these issues.

Ovulatory onset in girls was described 40 years ago by Prader, Metcalf and others, as noted in the current paper, and maturation of the hypothalamic pituitary ovarian axis irrespective of body mass index was recognised and described 20 years ago by Legro et al. The relationship between menstrual irregularity and polycystic ovary syndrome/metabolic syndrome is widely recognised and very well documented. Ibanez et al have studied premenarchal girls with premature pubarche, describing increased lifetime risk for metabolic syndrome. ${ }^{4}$ However, despite a wealth of information regarding the phenomenon of menstrual irregularity associated with PCOS, there is a minimal amount of published data on menstrual irregularity and ovulation rate in healthy girls. Venturoli, in $1987,{ }^{5}$ described a low rate of ovulation in $49 \%$ of 200 girls followed over a 6 -year period with only a few who ovulated regularly.

The current paper addresses this issue, providing further information on this important subject. Using subjects from the RAINE study, a prospectively examined birth cohort, examining perinatal influences on later health, the authors describe the presence of ovulation in 40 girls, $>25 \%$ of whom were overweight or obese, finding that $82.5 \%$ had evidence of ovulation, with $>80 \%$ occurring regularly. Differences from older study reports may relate to more precise ability to measure ovulation with accuracy. In addition, some adolescents with irregular menstrual cycles and irregular ovulation will normalise with the passage of time as a maturational event.

The conclusions drawn from the current paper, that menstrual irregularity should not be used as evidence of anovulation, have significant implications. First and most importantly, it informs paediatricians that their knowledge in menstrual patterns in adolescent females, with or without chronic disease, needs to be updated, that careful assessment of girls at regular intervals is necessary and that attention to information regarding contraception should be a routine part of adolescent health management for all. By extension, this should include, in particular, adolescents who have health conditions that may put them at increased risk in case of unplanned pregnancy, such as girls with cardiac conditions, transplant recipients, those with liver disease or bleeding disorders or where fetal risk may be incurred due to medication exposure.

Competing interests None declared.

Provenance and peer review Commissioned; internally peer reviewed.

(C) Article author(s) (or their employer(s) unless otherwise stated in the text of the article) 2018. All rights reserved. No commercial use is permitted unless otherwise expressly granted.

\section{Check for updates}

To cite Zacharin M. Arch Dis Child

2018;103:208-209.

Received 29 May 2017

Revised 17 October 2017

Accepted 1 November 2017

Published Online First 22 November 2017

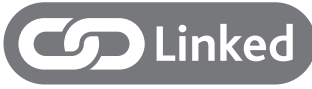

http://dx.doi.org/10.1136/archdischild-2017312968

Arch Dis Child 2018;103:208-209.

doi:10.1136/archdischild-2017-313417

\section{REFERENCES}

1 Peña AS, Doherty DA, Atkinson HC, et al. The majority of irregular menstrual cycles in adolescence are ovulatory: results of a prospective study. Arch Dis Child 2018;103:235-9.

2 Hokken-Koelega A, van der Lely AJ, Hauffa B, et al. Bridging the gap: metabolic and endocrine care of patients during transition. Endocr Connect 2016;5:R44-R54

3 Gluckman PD, Hanson MA. The consequences of being born small - an adaptive perspective. Horm Res 2006;65(Suppl 3):5-14.

4 Ibáñez L, Díaz R, López-Bermejo A, et al. Clinical spectrum of premature pubarche: links to metabolic syndrome and ovarian hyperandrogenism. Rev Endocr Metab Disord 2009;10:63-76.

5 Venturoli S, Porcu E, Fabbri R, et al. Postmenarchal evolution of endocrine pattern and ovarian aspects in adolescents with menstrual irregularities. Fertil Steril 1987;48:78-85. 